\title{
Primary Care Clinician Decision-Making Around Surveillance Colonoscopies in Older Adults with Prior Adenomas
}

\author{
Nancy L. Schoenborn, MD, MHS, Cynthia M. Boyd, MD, MPH, Jacqueline Massare, BS, \\ Reuben Park, Youngjee Choi, MD, and Craig E. Pollack, MD, MHS
}

Introduction: While guidelines recommend against routine colorectal cancer screening in adults $>75$ years and/or those with limited life expectancies, there is no clear guidance on when surveillance colonoscopies following prior adenoma detection should stop. How primary care clinicians weigh the potential risks and benefits of surveillance colonoscopies in older adults with prior adenomas is unknown.

Methods: We conducted semistructured in-person interviews with 30 primary care clinicians from 21 clinics in Maryland. We asked how clinicians decided whether to continue or stop surveillance colonoscopies in older adults (65+ years) with prior adenomas. Interview transcripts were independently coded by 2 investigators using qualitative content analysis.

Results: Participants described a range of decision-making approaches. Some deferred to specialists because they did not feel confident making decisions about stopping surveillance in light of the higher cancer risk involved. Some took a more active role and discussed the decision with patients and/or specialists. Other clinicians felt comfortable stopping surveillance colonoscopies and made these decisions based on patient age, comorbidities, or life expectancy.

Discussion: We found a range of decision-making approaches among primary care clinicians on whether to continue surveillance colonoscopies in older adults with prior adenomas. Separate bodies of evidence currently exist on how prior adenoma characteristics influence colorectal cancer risk and on how older age and declining health influence the benefit/harm balance of screening. Information is lacking on the benefits and harms of surveillance in older adults with prior adenomas. Developing the evidence to address this knowledge gap is critically needed to inform clinical decision making. ( $\mathrm{J}$ Am Board Fam Med 2020;33:796-798.)

Keywords: Aging, Clinical Decision Making, Colonoscopy, Colorectal Cancer, Decision Making, Early Detection of Cancer, Life Expectancy, Maryland, Mass Screening, Primary Health Care, Qualitative Research, Risk Assessment

\section{Introduction}

High-quality screening colonoscopies are expected to have an adenoma detection rate of at least $25 \%$, resulting in a large number of older adults (65+ years)

This article was externally peer reviewed.

Submitted 18 December 2019; revised 14 April 2020; accepted 14 April 2020.

From the Johns Hopkins University School of Medicine, Baltimore, MD (NLS, CMB, JM, YC); The Johns Hopkins University, Baltimore, MD (RP); The Johns Hopkins University School of Public Health, Baltimore, MD (CEP).

Author Contributions: NLS had full access to all of the data in the study and takes responsibility for the integrity of the data and the accuracy of the data analysis. Design and conduct of the study: NLS, CMB, YC, CEP. Data collection and management: NLS, JM. Data analysis and interpretation: NLS, JM, Park, Boyd, Choi, CEP. Preparation with history of adenomas. ${ }^{1}$ While guidelines recommend against routine colorectal cancer screening in adults $>75$ years and/or those with limited life expectancies, ${ }^{2,3}$ there is no clear guidance on when

of the manuscript: NLS. Review and revision of the manuscript: NLS, JM, RP, CMB, YC, CEP.

Funding: This project was made possible by Grant No. K76AG059984 from the National Institute on Aging. In addition, CMB was supported by Grant No. 1K24AG056578 from the National Institute on Aging. The funding sources had no role in the design, methods, subject recruitment, data collections, analysis and preparation of paper.

Conflict of interest: CEP owns stock ownership in Gilead Sciences, Inc.

Corresponding author: Nancy L. Schoenborn, MD, 5200 Eastern Avenue, Mason F. Lord, Building Center Tower, Room 703, Baltimore, MD 21224 (E-mail: nancyli@jhmi.edu). 
surveillance colonoscopies following prior adenoma detection should stop. How primary care clinicians weigh the potential risks and benefits of surveillance colonoscopies in older adults with prior adenomas has not been previously explored.

\section{Methods}

We conducted semistructured in-person interviews with 30 primary care clinicians from 21 clinics in Maryland. Clinicians were recruited from academic geriatric and primary care clinics affiliated with Johns Hopkins Medicine; the Johns Hopkins Community Physicians, which is the largest outpatient community group practice in Maryland; and 16 private practices not affiliated with Johns Hopkins Medicine. Maximum variation sampling sought to recruit clinicians diverse in age, gender, clinician type, specialty, and practice type. We asked how clinicians decided whether to continue or stop surveillance colonoscopies in older patients 65 years or older with prior adenomas. Data collection (October 2018 to May 2019) was guided by iterative assessment for theme saturation. The interviews were audio-recorded, transcribed verbatim, and was independently coded by 3 investigators (NS, JM, RP) using qualitative content analysis.

\section{Results}

Participants described a range of decision-making approaches (Table 1). Most commonly, participants said that they would defer to gastroenterologists to make decisions about stopping surveillance colonoscopies (12/30). Some participants mentioned that they would discuss the decision with the patients and/or specialists and make the decision together $(5 / 30)$.

A subset of participants was more comfortable with stopping surveillance colonoscopies (7/30) and described the scenarios in which they would do so. Some mentioned specific age cutoffs-stopping surveillance at age 80 or age 85 years. Some said that they would stop surveillance when patients have limited life expectancy and/or multiple serious health conditions. One clinician described individualizing the decision based on the recommended interval at which to repeat the surveillance colonoscopy and the patient's predicted life expectancy

"First I make sure that I agree with the interval [that is] being recommended. . then I stop when the patient
Table 1. Characteristics and Responses from 30 Maryland Primary Care Clinicians on Decision Making about Colorectal Cancer Surveillance in Older Patients with Prior Adenomas (Data Collection October 2018 to May 2019)

\begin{tabular}{|c|c|}
\hline Characteristics & $\begin{array}{l}\text { No. }(\%) \text { or } \\
\text { Mean (SD) }\end{array}$ \\
\hline Age, years & $48.2(10.0)$ \\
\hline Female sex & $16(53 \%)$ \\
\hline \multicolumn{2}{|l|}{ Race } \\
\hline White & $18(60 \%)$ \\
\hline African American & $6(20 \%)$ \\
\hline Other & $6(20 \%)$ \\
\hline \multicolumn{2}{|l|}{ Degree } \\
\hline Physician & $24(80 \%)$ \\
\hline Certified registered nurse practitioner & $5(17 \%)$ \\
\hline Physician's assistant & $1(3 \%)$ \\
\hline Years since completing training & $17.5(10.2)$ \\
\hline \multicolumn{2}{|l|}{ Specialty } \\
\hline Internal medicine & $17(57 \%)$ \\
\hline Family medicine & $6(20 \%)$ \\
\hline Medicine/pediatrics & $2(7 \%)$ \\
\hline Geriatrics & $5(17 \%)$ \\
\hline \multicolumn{2}{|l|}{ Clinic site } \\
\hline Urban & $13(43 \%)$ \\
\hline Suburban & $17(57 \%)$ \\
\hline \multicolumn{2}{|l|}{ Clinic type } \\
\hline Clinics affiliated with academic university & $8(27 \%)$ \\
\hline Clinics within a large group practice & $14(47 \%)$ \\
\hline Solo clinics & $5(17 \%)$ \\
\hline House-call program for homebound patients & $1(3 \%)$ \\
\hline Program for all-inclusive care of the elderly & $2(7 \%)$ \\
\hline \multicolumn{2}{|l|}{$\begin{array}{l}\text { Proportion of patients } \geq 65 \text { years old in patient } \\
\text { panel }\end{array}$} \\
\hline$<25 \%$ & $7(23 \%)$ \\
\hline $25 \%$ to $49 \%$ & $13(43 \%)$ \\
\hline $50 \%$ to $74 \%$ & $4(13 \%)$ \\
\hline$>75 \%$ & $6(20 \%)$ \\
\hline \multicolumn{2}{|l|}{$\begin{array}{l}\text { Decision-making approach regarding surveillance } \\
\text { in older patients with prior adenomas* }\end{array}$} \\
\hline Deferred to GI & $12(40 \%)$ \\
\hline $\begin{array}{l}\text { Discussed with patient and/or GI to make } \\
\text { decision together }\end{array}$ & $5(17 \%)$ \\
\hline $\begin{array}{l}\text { Described stopping surveillance based on } \\
\text { patient age, comorbidities, or life expectancy }\end{array}$ & $7(23 \%)$ \\
\hline Favored continued surveillance & $1(3 \%)$ \\
\hline $\begin{array}{l}\text { Decision depended on specific patient } \\
\text { characteristics }\end{array}$ & $3(10 \%)$ \\
\hline
\end{tabular}

GI, gastroenterology; SD, standard deviation.

*Two participants did not give direct responses about decision making around surveillance colonoscopies in the interviews.

is within that number of years of death. So if it's 1 or 2 not very concerning polyps under a centimeter... and they are on a 5-year plan then I'm gonna stop 5 
years before death. Someone who has had multiple polyps greater than a centimeter... on a 3-year or shorter interval we are probably not gonna stop until we really see a life-ending diagnosis."

Others (3/30) said the decision would depend on specific patient characteristics, such as the size, number, and pathology of the adenomas. One participant expressed worry about missing colorectal cancers and said that at times he preferred patients to continue surveillance even when gastroenterologists had suggested stopping. Two participants commented that decisions around surveillance colonoscopies were challenging but did not provide details on their decision-making approaches.

\section{Discussion}

We found a range of decision-making approaches among primary care clinicians on whether to continue surveillance colonoscopies in older adults with prior adenomas. Many deferred to gastroenterologist recommendations; however, literature suggests that gastroenterologists tend to recommend earlier followup compared with guidelines contributing to overuse of colonoscopies. ${ }^{4}$ Although some primary care clinicians mentioned making surveillance decisions based on patient age, comorbidities, or life expectancy, we found no consensus on how these factors were weighed against the history of adenomas. Separate bodies of evidence exist on how prior adenoma characteristics influence colorectal cancer risk and on how older age and declining health influence the benefit/harm balance of screening. ${ }^{2,3,5}$ Information is lacking on the benefits and harms of surveillance in older adults with prior adenomas. Developing the evidence to address this knowledge gap is critically needed to inform clinical decision making.

To see this article online, please go to: http://jabfm.org/content/ 33/5/796.full.

\section{References}

1. Rex DK, Boland CR, Dominitz JA, et al. Colorectal cancer screening: recommendations for physicians and patients from the U.S. Multi-Society Task Force on Colorectal Cancer. Gastroenterology 2017;153: 307-23.

2. Lin JS, Piper MA, Perdue LA, et al. Screening for colorectal cancer: updated evidence report and systematic review for the US Preventive Services Task Force. JAMA 2016;315:2576-94.

3. Qaseem A, Crandall CJ, Mustafa RA, Hicks LA, Wilt TJ. Clinical Guidelines Committee of the American College of Physicians. Screening for colorectal cancer in asymptomatic average-risk adults: a guidance statement from the American College of Physicians. Ann Intern Med 2019;171:643-54.

4. Kruse GR, Khan SM, Zaslavsky AM, Ayanian JZ, Sequist TD. Overuse of colonoscopy for colorectal cancer screening and surveillance. J Gen Intern Med 2015;30:277-83.

5. Gupta S, Lieberman D, Anderson JC, et al. Recommendations for follow-up after colonoscopy and polypectomy: a consensus update by the US Multi-Society Task Force on Colorectal Cancer. Gastroenterology 2020;158:1131-53.e5. 